\title{
DESIGN AND CONSTRUCTION OF A LAW COST SMOKING MACHINE FOR TOBACCO SMOKE GENERATION AND DEMONSTRATION THE SMOKERS INTAKE
}

\author{
UNP Udawatte and KRR Mahanama \\ Department of Chemistry, University of Colombo, Colombo 03
}

Consumption of tobacco products has been deteriorati ig human health for centuries. As a result tobacco smoke research has been carried out to understand the health impact to the active smokers as well as passive smokers. However no attempt has been made to evaluate the implicating to Sri Lankan population presumably dik to lack of research facilities and interest. This project was initiated to fill the existing void.

Initial step of tobacco smoke research is the gereration of tobacco smoke. Nearly all the researches have employed standard smoking conditions prescribe by tobacco research council using a smoking maching to stimulate the smokers. Thus generated smoke for mainstream and side stream is collected separately to evaluate the health impact to active and passive smokers respectively. In addition, the information genera e 1 using standard conditions enable the researches to compare their results with the others it interpreting the health consequences.

Initiating the tobacco smoke research, our primary objective was to construct a smoking machine, which is not commerciallyt available in S i Lanka. A user-friendly smoking machine was design and constructed for a cost of two thousani Sri Lankan rupees. Which is at least 50 times less expensive than a foreign smoking machine. Yet it simulates the actual smoking conditions generate the mainstream and the side stream separately for the analysis.

The constructed smoking maching also utilized to cemonstrates the intake of smoke and its deposition in the respiratory tract of a smoker. Here the mainstream smoke emitted from the marchine was directed through a transparent tube sim lating the passage through the respiratory tract. This set up can be utilized in public awareness programmes to demote the smoking practices among the Sri Lankan public. Reproducible smoke generation, ability to change the smoking parameters and the low cost are some of the attractive features of the constructed multipurpose smoking machine. 